\title{
Preface
}

\author{
Ender Özcan ${ }^{1}$ • Edmund K. Burke ${ }^{2}$. \\ Barry McCollum ${ }^{3}$
}

Published online: 25 March 2017

(C) Springer Science+Business Media New York 2017

\section{The Practice and Theory of Automated Timetabling (2014)}

Welcome to this special issue of the Annals of Operations Research which draws upon a carefully selected portfolio of papers from the 10th International Conference on the Practice and Theory of Automated Timetabling (PATAT) in York, United Kingdom between 26th and 29th August 2014. These conferences have been held biennially since 1995, with one exception being the three-year gap between the 1997 conference in Toronto and the 2000 conference in Konstanz. This is the fourth time that the Annals of Operations Research has acted as a repository for a selection of expanded versions of our strongest papers.

The PATAT series is focused around multidisciplinary approaches, techniques, and methods for all types of timetabling problems. It cuts across both theory and practice and is particularly concerned with the issue of closing the gap between these two aspects of the research landscape. The conference in York brought over 130 delegates together from all around the world. We had 5 plenary presentations, 64 standard talks, and 5 system demonstrations. This body of work forms the basis of the selection pool for this special issue although we also provided a public call for papers to supplement this. All of the submissions have been subjected to a rigorous and thorough review process by experts in the field.

We would like to thank the PATAT Programme Committee and other reviewers for their hard work and support in the selection process. We are also grateful to the sponsors, Organising Committee, and all individuals who have helped make the conference such a success, in

\footnotetext{
Ender Özcan

ender.ozcan@nottingham.ac.uk

Edmund K. Burke

e.burke@qmul.ac.uk

Barry McCollum

b.mccollum@qub.ac.uk

1 School of Computer Science, University of Nottingham, Nottingham, UK

2 Queen Mary University of London, London, UK

3 Queens University, Belfast, UK
} 
particular, Angeliki Gretista who helped on the reception desk. In addition, we would like to extend our thanks to all the members of the Steering Committee who work so hard to ensure the continuation of the series. Finally, of course, we thank all authors and delegates for their contributions. 